\title{
Identification of androgen-regulated genes in human prostate
}

\author{
MARKKU H. VAARALA ${ }^{1,2}$, PASI HIRVIKOSKI ${ }^{3}$, SAILA KAUPPILA ${ }^{2}$ and TIMO K. PAAVONEN ${ }^{4}$ \\ ${ }^{1}$ Department of Surgery, Oulu University Hospital, FIN-90029 Oulu; ${ }^{2}$ Department of Pathology, University of Oulu, \\ FIN-90014 Oulu; ${ }^{3}$ Department of Pathology, Oulu University Hospital and Länsi-Pohja Central Hospital, FIN-90029 Oulu; \\ ${ }^{4}$ Department of Pathology, University of Tampere and Tampere University Hospital, \\ School of Medicine, FIN-33014 Tampere, Finland
}

Received February 21, 2012; Accepted June 15, 2012

DOI: $10.3892 / \mathrm{mmr} .2012 .956$

\begin{abstract}
Androgens are essential for the development of the prostate and prostate cancer. We examined androgen-regulated gene expression in the human prostate. Samples from benign and malignant prostate tissue and samples containing prostate tissue obtained from prostate cancer patients three days after surgical castration were further processed as probes for a GeneChip array. The comparison of gene expression profiles in castrated samples and in benign or malignant prostate tissue samples revealed androgen-regulated genes. We further evaluated the genes which were differentially expressed in benign and malignant prostate samples. The androgen-regulated expression of dual specificity phosphatase 1 (DUSP1) was confirmed in the LNCaP prostate cancer cell line, as the expression of DUSP1 increased with androgen treatment over the course of time. The expression of the genes CRISP3, PCA3, OR51E2, HOXC6, AGR3, AMACR and SLC14A1 was affected by castration in addition to differential expression in the benign and malignant prostate. These sample results require further investigation for the role of AGR3 and SLC14A1 in prostate cancer as these associations have not been reported previously.
\end{abstract}

\section{Introduction}

Androgen action is essential for the development of the prostate and also for the development of prostate cancer. Androgen deprivation therapy is a fundamental treatment for metastasised prostate cancer. The activity of androgens is mediated mainly via the androgen receptor (AR), although other androgen responsive activation mechanisms may exist, especially in hormone-refractory prostate cancer (1). Androgen-regulated gene expression has been investigated in

Correspondence to: Dr Markku H. Vaarala, Department of Surgery, University of Oulu, P.O. Box 5000, FIN-90014, Finland E-mail: markku.vaarala@oulu.fi

Key words: gene expression, prostate cancer, benign prostatic hyperplasia, castration numerous studies using prostate cancer cell lines. However, to the best of our knowledge, only a few studies have used human tissues to evaluate androgen-regulated genes. One study reported gene expression changes following castration using prostatectomy samples after three months of androgen deprivation therapy (combination of anti-androgen and chemical castration) (2). In another study, a comparison was made of the expression profiles of untreated and androgenindependent prostate cancer (3). Mostaghel et al (4) studied gene expression changes in human prostate tissue at different time points up to nine months after castration for the treatment of localised prostate cancer. The same group further examined the effect of the 5- $\alpha$ reductase inhibitor dutasteride on prostate gene expression (5). The aim of the present study was to identify androgen-regulated genes in the human prostate. Gene expression analysis was performed on human prostate tissue samples from benign and malignant prostate tissue and from prostate biopsy samples obtained three days after surgical castration.

\section{Materials and methods}

Patient samples. Prostate samples were collected from three patients undergoing radical prostatectomy for the treatment of prostate cancer. Prostate biopsy samples were obtained from another three patients three days after surgical castration performed as treatment for prostate cancer. These male individuals had newly diagnosed prostate cancer with no previous hormonal treatments. The biopsies were extracted using a biopsy gun technique and $18 \mathrm{G}$ needles. Six biopsies were obtained and a single prophylactic dose of ciprofloxacin (500 mg) was administered. Written informed consent was obtained from every patient giving tissue samples for the study. The study was approved by the Ethics Council of the Northern Ostrobothnia Hospital District. RNA from the samples was isolated using the QuickPrep Total RNA Extraction kit (Amersham Biosciences, Piscataway, NJ, USA) according to the manufacturer's instructions. The RNA from the samples was individually labelled and used for the GeneChip array. Three samples were microdissected and histologically confirmed as benign prostate tissue from radical prostatectomy specimens, and three samples were microdissected and histologically confirmed as Gleason $3+3$ prostate cancer tissue 
from radical prostatectomy specimens and three samples were from biopsies taken following surgical castration performed as a therapeutic procedure for prostate cancer.

Cell culture. The prostate cancer cell line LNCaP (CRL-1740) was purchased from the American Type Culture Collection (ATCC, Manassas, VA, USA). LNCaP cell cultures were maintained in RPMI-1640 (Sigma-Aldrich, St. Louis, MO, USA) supplemented with $10 \mathrm{mM}$ HEPES, $1 \mathrm{mM}$ sodium pyruvate and $2.5 \mathrm{~g} / 1 \mathrm{D}$-glucose or DMEM (Sigma-Aldrich) supplemented with $4,500 \mathrm{mg} / \mathrm{l}$ glucose, L-glutamine and $1 \%$ penicillin-streptomycin (Invitrogen-Gibco, Carlsbad, CA, USA). The cell cultures were supplemented with $10 \%$ foetal bovine serum (FBS) (HyClone, Logan, UT, USA) at $37^{\circ} \mathrm{C}$ in a humidified atmosphere of $5 \% \mathrm{CO}_{2}$. FBS was substituted with charcoal-treated FBS in the hormone-induction experiments. The LNCaP cells were plated at $1 \times 10^{6}$ cells/plate $72 \mathrm{~h}$ prior to the experiments. The cells were treated with $10 \mathrm{nM}$ R1881 (PerkinElmer, Boston, MA, USA) or an equal volume of ethanol for $0,6,24$, or $48 \mathrm{~h}$. Following incubation, the cells were collected, washed with phosphate-buffered saline and used directly for the isolation of RNA.

GeneChip protocol. Experimental procedures for GeneChip were performed according to the Affymetrix GeneChip Expression Analysis Technical Manual following the microarray experiment guidelines. In brief, using $8 \mu \mathrm{g}$ of total RNA as a template, double-stranded DNA was synthesised using the One-Cycle cDNA Synthesis kit (Affymetrix, Santa Clara, CA, USA) and T7-(dT)24 primers. The DNA was purified using a GeneChip Sample Cleanup Module (Qiagen, Venlo, The Netherlands). In vitro transcription was performed to produce biotin-labeled cRNA using an in vitro transcription labeling kit (Affymetrix), according to the manufacturer's instructions. Biotinylated cRNA was cleaned with a GeneChip Sample Cleanup Module (Qiagen), fragmented to 35-200 nucleotides and hybridised to Affymetrix Human Genome U133 Plus 2 arrays that contained 55,000 human transcripts. After being washed, the array was stained with streptavidin-phycoerythrin (Molecular Probes, Eugene, OR, USA). The staining signal was amplified using biotinylated anti-streptavidin (Vector Laboratories, Burlingame, CA, USA) and a second staining was performed with streptavidinphycoerythrin before the array was scanned on a GeneChip Scanner 3000. The expression data were analysed using Affymetrix GeneChip Operating System Software. Signal intensities of all probe sets were scaled to the target value of 500 .

Quantitative reverse transcription-polymerase chain reaction (RT-PCR). Total RNA from LNCaP cells for quantitative RT-PCR measurements was isolated with TRIzol reagent (Invitrogen-Gibco) according to the manufacturer's instructions. Using the First-Strand cDNA synthesis kit (Amersham Biosciences) the first-strand cDNA was synthesised with $1 \mu \mathrm{g}$ of RNA and $\operatorname{pd}(\mathrm{N}) 6$ random hex deoxynucleotides according to the manufacturer's instructions. The mRNA levels for LNCaP cells were measured by quantitative RT-PCR analysis (ABI 7700, Applied Biosystems, Foster City, CA, USA) as described previously (6). The forward and reverse primers for for the detection of dual specificity phosphatase 1 (DUSP1) mRNA were 5'-TCCTTCTTCGCTTTCAACGC-3' and 5'-ACGATGGTGCTGAAGCGC-3', respectively. Amplicons were detected using the fluorogenic probe 5'-FAM-CACA TCGCCGGCTCTGTCAACG-TAMRA-3'. The primers and probe for the $18 \mathrm{~S}$ amplicon were 5'-TGGTTGCAAAGCTGA AACTTAAAG-3' (forward), 5'-AGTCAAATTAAGCCGCA GGC-3' (reverse) and 5'-VIC-CCTGGTGGTGCCCTTCCG TCA-TAMRA-3', respectively.

Analysis of gene expression profiles. The expression profiles from the GeneChip array were analysed using Chipster software (http://chipster.csc.fi). The GeneChips were normalised using the robust multiarray average (RMA) method and gene expression intensity estimates were received in log2-transformed values. The pathways involved were identified using Chipster software utilising data from ConsensusPathDB (7). The data discussed in this study have been deposited in the NCBI's Gene Expression Omnibus (8) and are accessible through GEO Series accession number GSE32982 (http:// www.ncbi.nlm.nih.gov/geo/query/acc.cgi?acc=GSE32982).

Statistical analysis. Statistical analysis of the levels of DUSP1 mRNA in LNCaP cells was performed using SPSS version 15.0 (SPSS, Chicago, IL, USA). The Student's t-test was used for comparison between the two groups. Values were presented as the means $\pm \mathrm{SD}$.

\section{Results}

Genes differentially expressed in prostate cancer and benign prostate tissue, and genes differentially expressed in benign prostate tissue or prostate cancer and castrated prostate cancer are listed in Table I. These genes contain several well-known androgen-regulated genes and prostate cancer-associated genes, including MSMB, SORD, CRISP3 and PCGEM1. The consensus pathways involved between benign and malignant tissue and between benign tissue and castrated prostate cancer are shown in Table II.

The androgen-regulated expression of DUSP1 in LNCaP prostate cancer cell lines was also evaluated (Fig. 1). The treatment of LNCaP cells with synthetic androgen R1881 led to an increased expression of DUSP1 mRNA, with a peak of 2.6-fold expression following $48 \mathrm{~h}$ of treatment compared with androgen-depleted conditions.

\section{Discussion}

To identify androgen-regulated genes in the human prostate, we used human prostate tissue mRNAs in a GeneChip array. The main limitation of widely used human prostate cancer cell lines such as LNCaP, PC-3 and DU-145 is that they do not represent the prostate per se, but are isolated from a prostate cancer metastasis. We evaluated the gene expression profiles from microdissected tissue samples from freshly prepared radical prostatectomy samples and from transrectal prostate biopsies obtained three days after surgical castration performed as a treatment for prostate cancer.

Certain known androgen-regulated genes were identified, including MSMB (9) and SORD (10). Furthermore, a number 
Table I. Differentially expressed genes in benign prostate tissue samples, prostate cancer samples and samples obtained following surgical castration. ${ }^{\text {a }}$

Fold overexpression

Symbol

Description

P-value Cancer vs. benign Benign/cancer vs. castrated

\begin{tabular}{|c|c|c|c|c|}
\hline CRISP3 & Cysteine-rich secretory protein 3 & $<0.001$ & 5.78 & -3.08 \\
\hline FOS & $\begin{array}{l}\text { FBJ murine osteosarcoma viral oncogene } \\
\text { homologue }\end{array}$ & $<0.001$ & & 4.76 \\
\hline PCGEM1 & $\begin{array}{l}\text { Prostate-specific transcript } 1 \text { (non-protein } \\
\text { coding) }\end{array}$ & $<0.001$ & & 4.42 \\
\hline MYBPC1 & Myosin binding protein $\mathrm{C}$, slow type & $<0.001$ & & 4.30 \\
\hline PCA3 & Prostate cancer antigen 3 (non-protein coding) & $<0.001$ & 4.18 & 3.74 \\
\hline OR51E2 & $\begin{array}{l}\text { Olfactory receptor, family } 51 \text {, subfamily } \mathrm{E} \text {, } \\
\text { member } 2\end{array}$ & $<0.001$ & 4.01 & 3.29 \\
\hline ANPEP & Alanyl (membrane) aminopeptidase & $<0.001$ & & 3.84 \\
\hline DPP4 & Dipeptidyl-peptidase 4 & 0.005 & & 3.79 \\
\hline GCNT2 & $\begin{array}{l}\text { Glucosaminyl (N-acetyl) transferase } 2 \text {, } \\
\text { I-branching enzyme (I blood group) }\end{array}$ & 0.001 & & 3.73 \\
\hline HOXC6 & Homeobox C6 & 0.003 & 3.69 & -2.62 \\
\hline AGR3 & $\begin{array}{l}\text { Anterior gradient homologue } 3 \\
\text { (Xenopus laevis) }\end{array}$ & 0.003 & 3.63 & 3.00 \\
\hline RGS1 & Regulator of G-protein signalling 1 & 0.002 & & 3.55 \\
\hline NR4A2 & $\begin{array}{l}\text { Nuclear receptor subfamily } 4 \text {, group A, } \\
\text { member } 2\end{array}$ & 0.002 & & 3.50 \\
\hline DUSP1 & Dual specificity phosphatase 1 & 0.011 & & 3.48 \\
\hline AMACR & $\alpha$-methylacyl-CoA racemase & 0.008 & 3.40 & 3.00 \\
\hline LOC728606 & Hypothetical LOC728606 & 0.015 & & 3.36 \\
\hline DLX1 & Distal-less homeobox 1 & 0.011 & 3.30 & \\
\hline VEGFA & Vascular endothelial growth factor A & 0.004 & & 3.30 \\
\hline MSMB & Microseminoprotein, $\beta$ - & 0.006 & & 3.21 \\
\hline TDO2 & Tryptophan 2,3-dioxygenase & 0.025 & & 3.19 \\
\hline NCAPD3 & Non-SMC condensin II complex, subunit D3 & 0.008 & & 3.14 \\
\hline EGR1 & Early growth response 1 & 0.027 & & 3.14 \\
\hline CD38 & CD38 molecule & 0.008 & & 3.13 \\
\hline C15orf48 & Chromosome 15 open reading frame 48 & 0.022 & 3.11 & \\
\hline RASD1 & RAS, dexamethasone-induced 1 & 0.030 & & 3.09 \\
\hline AGR2 & $\begin{array}{l}\text { Anterior gradient homologue } 2 \\
\text { (Xenopus laevis) }\end{array}$ & 0.023 & 3.07 & \\
\hline SORD & Sorbitol dehydrogenase & 0.012 & & 3.02 \\
\hline C12orf56 & Chromosome 12 open reading frame 56 & 0.037 & & 3.01 \\
\hline SFTPA2 & Surfactant protein A2 & 0.037 & & 2.99 \\
\hline ST6GALNAC1 & $\begin{array}{l}\text { ST6 ( } \alpha \text {-N-acetyl-neuraminyl-2,3- } \beta \text { - } \\
\text { galactosyl-1,3)-N-acetylgalactosaminide } \\
\alpha-2,6 \text {-sialyltransferase } 1\end{array}$ & 0.038 & & 2.98 \\
\hline ACADL & Acyl-CoA dehydrogenase, long chain & 0.013 & & 2.98 \\
\hline EGR3 & Early growth response 3 & 0.044 & & 2.94 \\
\hline ERG & $\begin{array}{l}\text { V-ets erythroblastosis virus E26 oncogene } \\
\text { homologue (avian) }\end{array}$ & 0.045 & 2.90 & \\
\hline FOSB & $\begin{array}{l}\text { FBJ murine osteosarcoma viral oncogene } \\
\text { homologue B }\end{array}$ & 0.016 & & 2.90 \\
\hline SCD & Stearoyl-CoA desaturase ( $\delta$ - 9 -desaturase) & 0.024 & & 2.80 \\
\hline GNMT & Glycine N-methyltransferase & 0.028 & & 2.76 \\
\hline $\mathrm{CCK}$ & Cholecystokinin & 0.028 & & 2.75 \\
\hline PEBP4 & Phosphatidylethanolamine-binding protein 4 & 0.031 & & 2.72 \\
\hline ATF3 & Activating transcription factor 3 & 0.031 & & 2.71 \\
\hline HLA-DQA1 & Major histocompatibility complex, class II, & 0.032 & & 2.70 \\
\hline
\end{tabular}


Table I. Continued.

Fold overexpression

Symbol Description

P-value Cancer vs. benign Benign/cancer vs. castrated

\begin{tabular}{|c|c|c|c|c|}
\hline SELE & Selectin E & 0.035 & & 2.66 \\
\hline PENK & Proenkephalin & 0.043 & & 2.61 \\
\hline CD177 & CD177 molecule & 0.048 & & 2.58 \\
\hline MALAT1 & $\begin{array}{l}\text { Metastasis-associated lung adenocarcinoma } \\
\text { transcript } 1 \text { (non-protein coding) }\end{array}$ & 0.032 & & -2.69 \\
\hline ASPN & Asporin & 0.029 & & -2.74 \\
\hline PSPH & Phosphoserine phosphatase & 0.027 & & -2.77 \\
\hline SLC14A1 & $\begin{array}{l}\text { Solute carrier family } 14 \text { (urea transporter), } \\
\text { member } 1 \text { (Kidd blood group) }\end{array}$ & 0.048 & -2.88 & -3.05 \\
\hline HBB & Haemoglobin, $\beta$ & 0.016 & & -2.89 \\
\hline SCGB1A1 & $\begin{array}{l}\text { Secretoglobin, family } 1 \mathrm{~A}, \text { member } 1 \\
\text { (uteroglobin) }\end{array}$ & 0.045 & -2.91 & \\
\hline KRT14 & Keratin 14 & 0.032 & -2.99 & \\
\hline NEFH & Neurofilament, heavy polypeptide & 0.022 & -3.10 & \\
\hline TMEM45B & Transmembrane protein $45 \mathrm{~B}$ & 0.007 & & -3.16 \\
\hline GPM6A & Glycoprotein M6A & 0.027 & & -3.17 \\
\hline RLN1 & Relaxin 1 & 0.016 & -3.21 & \\
\hline GREM1 & Gremlin 1 & 0.004 & & -3.29 \\
\hline MME & Membrane metallo-endopeptidase & 0.004 & -3.57 & \\
\hline CXCL13 & Chemokine (C-X-C motif) ligand 13 & 0.003 & -3.67 & \\
\hline CYP3A5 & $\begin{array}{l}\text { Cytochrome P } 450 \text {, family } 3 \text {, subfamily A, } \\
\text { polypeptide } 5\end{array}$ & 0.001 & -3.92 & \\
\hline WIF1 & WNT inhibitory factor 1 & $<0.001$ & -4.14 & \\
\hline
\end{tabular}

${ }^{\mathrm{a}}$ Gene symbols and gene descriptions are presented. P-values for differential expression were produced using Chipster software. Only genes with P-values $<0.05$ are presented. Negative values in the fold overexpression column indicate that the gene was underexpressed in cancer compared with benign samples or underexpressed in benign or cancer samples compared with castrated samples.

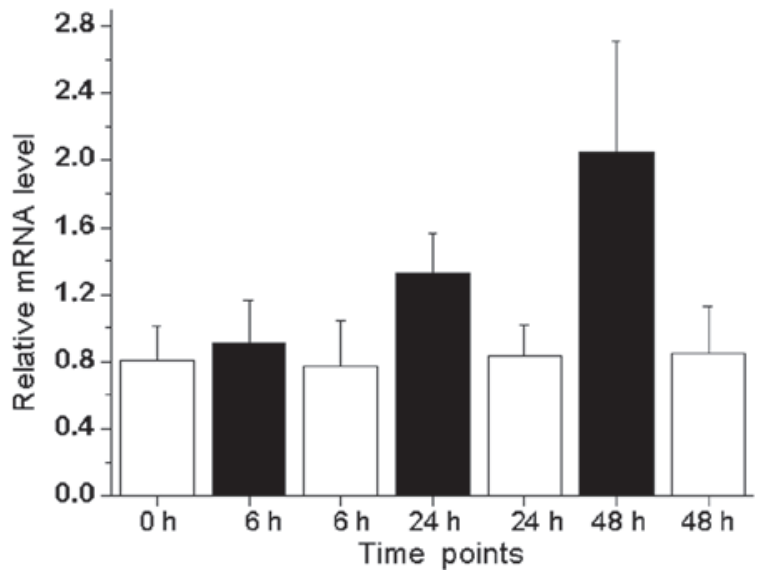

Figure 1. Response of DUSP1 mRNA in LNCaP cells following treatment with $10 \mathrm{nM}$ synthetic androgen R1881 (solid bars). Statistically significant induction of DUSP1 mRNA was observed after 24 and $48 \mathrm{~h}$ compared with the control after 24 and $48 \mathrm{~h}$ with $\mathrm{P}=0.04$ and $\mathrm{P}<0.001$, respectively. The values are the means \pm standard deviations of four individual samples. DUSP1, dual specificity phosphatase 1 .

of previously identified prostate cancer-associated genes, such as CRISP3 (11), PCGEM1 (12), PCA3 (13) and OR51E2 (also known as PSGR) (14) were also differentially expressed.
Cholesterol biosynthesis has several correlations with prostate cancer. Low serum cholesterol levels have been correlated with a lower risk of high-grade prostate cancer (15). Furthermore, the use of cholesterol-lowering drugs, such as statins, is associated with a lower risk of advanced prostate cancer (16). Increased cholesterol synthesis may serve as a precursor for intratumoural androgen synthesis in castration-resistant prostate cancer (17).

Focal adhesion pathways are involved in gene-expression changes between benign and malignant prostate tissue. Cell adhesion is a significant process in cancer (18). The steroid biosynthesis pathway was found to be active between the castrated and benign tissue, as expected.

DUSP1 (also known as mitogen-activated protein kinase phosphatase 1, MKP1) is androgen-regulated in the rat prostate (19). DUSP1 expression was detected in prostate cancer with a decreased expression in poorly differentiated carcinomas. Moreover, DUSP1 expression was downregulated in androgen-depleted clinical prostate cancer samples and the expression of DUSP1 was inversely correlated with apoptosis (20). In prostate cancer specimens, the expression of DUSP1 was low in hormone-refractory prostate cancer, whereas it was high in benign prostatic hyperplasia samples and in nonhormone-treated prostate cancer (21). The results of our study confirm those of previous results as DUSP1 expression was 
Table II. Pathways potentially active in the transition from benign to malignant prostate tissue and during surgical castration based on gene-expression differences. ${ }^{a}$

P-value

Pathway

Database

Benign tissue vs. cancer

Castrated tissue vs. benign tissue

AP-1_transcription_factor_network

Beta1_integrin_cell_surface_interactions

Bevacizumab_Pathway

Cholesterol_biosynthesis

Cholesterol_biosynthesis

cholesterol_biosynthesis_I

cholesterol_biosynthesis_II_

(via_24,25-dihydrolanosterol)

cholesterol_biosynthesis_III_(via_desmosterol) HumanCyc

Collagen_adhesion_via_alpha_2_beta_1_

glycoprotein

ECM-receptor_interaction_-_Homo_sapiens_ (human)

Fatty_Acyl-CoA_Biosynthesis

Focal_Adhesion

Focal_adhesion_-_Homo_sapiens_(human)

GPCR_signalling-cholera_toxin

GPCR_signalling-G_alpha_i

GPCR_signalling-pertussis_toxin

HIF-1-alpha_transcription_factor_network

Immunoregulatory_interactions_between_a_

Lymphoid_and_a_non-Lymphoid_cell

Integrin

Integrins_in_angiogenesis

Ketogenesis

Neurophilin_interactions_with_VEGF_and

VEGFR

Platelet_degranulation_

Prostaglandin_Synthesis_and_Regulation

Protein_digestion_and_absorption_-_Homo_ sapiens_(human)

Response_to_elevated_platelet_cytosolic_Ca ${ }^{2+}$

Signalling_by_PDGF

Signalling_by_VEGF

Smooth_Muscle_Contraction

Steroid_Biosynthesis

Steroid_biosynthesis_-_Homo_sapiens_(human)

Superpathway_of_cholesterol_biosynthesis

Syndecan-1-mediated_signalling_events

Valine_degradation_I

Vatalanib_Pathway

VEGF_ligand-receptor_interactions

Reactome

HumanCyc

HumanCyc

Reactome

Reactome

KEGG

INOH

INOH

INOH

PID

Reactome

HumanCyc

Reactome

Reactome

KEGG

Reactome

Reactome

Reactome

Reactome

SMPDB

KEGG

PID

HumanCyc

SMPDB

Reactome

$\begin{array}{lr}\text { PID } & 0.007 \\ \text { PID } & <0.001 \\ \text { SMPDB } & 0.006\end{array}$

Wikipathways

$<0.001$

0.002

0.003

0.003

0.003

0.001

$<0.001$

KEGG $\quad<0.001$

0.007

Wikipathways

0.004

0.003

0.004

0.003

0.006

0.006

0.008

$<0.001$

$<0.001$

INOH $\quad 0.006$

PID $\quad 0.004$

0.006

0.005

0.006

Wikipathways

0.007

0.002

0.007

$<0.001$

0.008

0.003

$<0.001$

0.002

$<0.001$

0.009

0.001

0.006

0.008

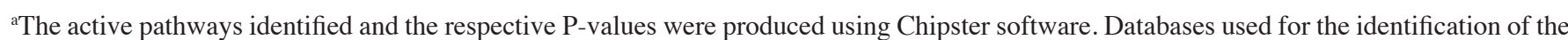
pathways are presented. PID, pathway interaction database; SMPDB, small molecule pathway database; KEGG, Kyoto encyclopedia of genes and genomes; INOH, integrating network objects with hierarchies.

3.48 times lower in castrated samples compared with benign or malignant prostate samples (Table I). We also provide data for the androgen-mediated induction of DUSP1 in androgen- sensitive LNCaP prostate cancer cell lines (Fig. 1). Taken together, it appears that DUSP1 is not important in hormonerefractory prostate cancer, as increased apoptosis detected in 
androgen-depleted prostate cancer by Magi-Galluzzi et al (20) may be explained by the low expression of DUSP1 under androgen-depleted conditions and high apoptotic indices under the same conditions in hormone-sensitive prostate cancer. The low expression of DUSP1 in hormone-refractory prostate cancer (21) may be explained by the androgen-dependent expression of DUSP1 shown in our study and previously by Leav et al (19), as castration is an ongoing process in hormonerefractory prostate cancer.

Of note are the genes that are differentially expressed in benign tissue and cancer, which are also overexpressed or underexpressed following castration, meaning that the gene is regulated by androgens and potentially involved in prostate carcinogenesis. These genes are CRISP3, PCA3, OR51E2, HOXC6, AGR3, AMACR and SLC14A1 (Table I). To the best of our knowledge, the association between prostate cancer and AGR3 or SLC14A1 has yet to be established. A high level of the immunoexpression of AGR3 has been linked with prolonged survival in ovarian cancer (22) and AGR3 expression has previously been detected in breast tumours (23). SLC14A1 was recently described as a urinary bladder cancer susceptibility gene (24).

Certain well-known androgen-regulated genes, such as kallikreins $(25,26)$, are not shown in Table I. This is due to the variation in gene expression levels in different samples leading to increased P-values. Thus genes, such as kallikreins, did not exceed the given threshold level of $\mathrm{P}<0.05$ for genes presented in Table I (data not shown). The number of samples analysed in our study was limited (three samples per group) and the biopsies obtained from castrated patients were random biopsies, thus these samples may represent cancer or benign tissue, or both. Despite these limitations, our data may be valuable for further studies in prostate cancer.

In conclusion, we have described the identification of androgen-regulated genes in the human prostate, some of which are potential new diagnostic or therapeutic targets in prostate cancer. Particular attention should be paid to AGR3 and SLC14A1 for their roles in prostate cancer. Furthermore, these gene expression profiles may be useful in sophisticated gene expression analyses utilising expression profiles from several different sources.

\section{Acknowledgements}

We are grateful to Ms. Mirja Mäkeläinen, Ms. Tarja Piispanen and Ms. Marja Tolppanen for technical assistance. Dr Mika Ilves performed the quantitative RT-PCR experiments. Dr Jussi Vuoristo performed the GeneChip arrays. The computations presented in this document were performed by the Centre for Scientific Computing (CSC) environment. CSC is the Finnish IT centre for science and is owned by the Ministry of Education. This study was supported by grants from the Finnish Medical Fund, the Päivikki and Sakari Sohlberg Foundation and the Urologic Research Foundation, Finland.

\section{References}

1. Bennett NC, Gardiner RA, Hooper JD, Johnson DW and Gobe GC: Molecular cell biology of androgen receptor signalling. Int J Biochem Cell Biol 42: 813-827, 2010.
2. Holzbeierlein J, Lal P, LaTulippe E, Smith A, Satagopan J, Zhang L, Ryan C, Smith S, Scher H, Scardino P, et al: Gene expression analysis of human prostate carcinoma during hormonal therapy identifies androgen-responsive genes and mechanisms of therapy resistance. Am J Pathol 164: 217-227, 2004.

3. Best CJ, Gillespie JW, Yi Y, Chandramouli GV, Perlmutter MA Gathright Y, Erickson HS, Georgevich L, Tangrea MA, Duray PH, et al: Molecular alterations in primary prostate cancer after androgen ablation therapy. Clin Cancer Res 11: 6823-6834, 2005.

4. Mostaghel EA, Page ST, Lin DW, Fazli L, Coleman IM, True LD, Knudsen B, Hess DL, Nelson CC, Matsumoto AM, et al: Intraprostatic androgens and androgen-regulated gene expression persist after testosterone suppression: therapeutic implications for castration-resistant prostate cancer. Cancer Res 67: 5033-5041, 2007.

5. Mostaghel EA, Geng L, Holcomb I, Coleman IM, Lucas J, True LD and Nelson PS: Variability in the androgen response of prostate epithelium to 5alpha-reductase inhibition: implications for prostate cancer chemoprevention. Cancer Res 70: 1286-1295, 2010.

6. Majalahti-Palviainen T, Hirvinen M, Tervonen V, Ilves M, Ruskoaho H and Vuolteenaho O: Gene structure of a new cardiac peptide hormone: a model for heart-specific gene expression. Endocrinology 141: 731-740, 2000.

7. Kamburov A, Wierling C, Lehrach $\mathrm{H}$ and Herwig R: ConsensusPathDB--a database for integrating human functional interaction networks. Nucleic Acids Res 37: D623-D628, 2009.

8. Edgar R, Domrachev M and Lash AE: Gene expression Omnibus: NCBI gene expression and hybridization array data repository. Nucleic Acids Res 30: 207-210, 2002.

9. Dahlman A, Edsjö A, Halldén C, Persson JL, Fine SW, Lilja $\mathrm{H}$, Gerald $\mathrm{W}$ and Bjartell A: Effect of androgen deprivation therapy on the expression of prostate cancer biomarkers MSMB and MSMB-binding protein CRISP3. Prostate Cancer Prostatic Dis 13: 369-375, 2010

10. Szabo Z, Hamalainen J, Loikkanen I, Moilanen AM, Hirvikoski P, Vaisanen T, Paavonen TK and Vaarala MH: Sorbitol dehydrogenase expression is regulated by androgens in the human prostate. Oncol Rep 23: 1233-1239, 2010.

11. Bjartell A, Johansson R, Bjork T, Gadaleanu V, Lundwall A, Lilja H, Kjeldsen L and Udby L: Immunohistochemical detection of cysteine-rich secretory protein 3 in tissue and in serum from men with cancer or benign enlargement of the prostate gland. Prostate 66: 591-603, 2006

12. Srikantan V, Zou Z, Petrovics G, Xu L, Augustus M, Davis L, Livezey JR, Connell T, Sesterhenn IA, Yoshino K, et al: PCGEM1, a prostate-specific gene, is overexpressed in prostate cancer. Proc Natl Acad Sci USA 97: 12216-12221, 2000.

13. de Kok JB, Verhaegh GW, Roelofs RW, Hessels D, Kiemeney LA, Aalders TW, Swinkels DW and Schalken JA: DD3(PCA3), a very sensitive and specific marker to detect prostate tumors. Cancer Res 62: 2695-2698, 2002.

14. Xu LL, Stackhouse BG, Florence K, Zhang W, Shanmugam N, Sesterhenn IA, Zou Z, Srikantan V, Augustus M, Roschke V, et al: PSGR, a novel prostate-specific gene with homology to a $\mathrm{G}$ protein-coupled receptor, is overexpressed in prostate cancer. Cancer Res 60: 6568-6572, 2000.

15. Platz EA, Till C, Goodman PJ, Parnes HL, Figg WD, Albanes D, Neuhouser ML, Klein EA, Thompson IM Jr and Kristal AR: Men with low serum cholesterol have a lower risk of high-grade prostate cancer in the placebo arm of the prostate cancer prevention trial. Cancer Epidemiol Biomarkers Prev 18: 2807-2813, 2009.

16. Murtola TJ, Tammela TL, Lahtela J and Auvinen A: Cholesterollowering drugs and prostate cancer risk: a population-based case-control study. Cancer Epidemiol Biomarkers Prev 16: 2226-2232, 2007.

17. Leon CG, Locke JA, Adomat HH, Etinger SL, Twiddy AL, Neumann RD, Nelson CC, Guns ES and Wasan KM: Alterations in cholesterol regulation contribute to the production of intratumoral androgens during progression to castration-resistant prostate cancer in a mouse xenograft model. Prostate 70: 390-400, 2010.

18. Mol AJ, Geldof AA, Meijer GA, van der Poel HG and van Moorselaar RJ: New experimental markers for early detection of high-risk prostate cancer: role of cell-cell adhesion and cell migration. J Cancer Res Clin Oncol 133: 687-695, 2007.

19. Leav I, Galluzzi CM, Ziar J, Stork PJ, Ho SM and Loda M: Mitogen-activated protein kinase and mitogen-activated kinase phosphatase-1 expression in the Noble rat model of sex hormoneinduced prostatic dysplasia and carcinoma. Lab Invest 75: 361-370, 1996. 
20. Magi-Galluzzi C, Mishra R, Fiorentino M, Montironi R, Yao H, Capodieci P, Wishnow K, Kaplan I, Stork PJ and Loda M: Mitogen-activated protein kinase phosphatase 1 is overexpressed in prostate cancers and is inversely related to apoptosis. Lab Invest 76: 37-51, 1997.

21. Rauhala HE, Porkka KP, Tolonen TT, Martikainen PM, Tammela TL and Visakorpi T: Dual-specificity phosphatase 1 and serum/glucocorticoid-regulated kinase are downregulated in prostate cancer. Int J Cancer 117: 738-745, 2005.

22. King ER, Tung CS, Tsang YT, Zu Z, Lok GT, Deavers MT, Malpica A, Wolf JK, Lu KH, Birrer MJ, Mok SC, et al: The anterior gradient homolog 3 (AGR3) gene is associated with differentiation and survival in ovarian cancer. Am J Surg Pathol 35: 904-912, 2011

23. Fletcher GC, Patel S, Tyson K, Adam PJ, Schenker M, Loader JA, Daviet L, Legrain P, Parekh R, Harris AL and Terrett JA: hAG-2 and hAG-3, human homologues of genes involved in differentiation, are associated with oestrogen receptor-positive breast tumours and interact with metastasis gene $\mathrm{C} 4.4 \mathrm{a}$ and dystroglycan. Br J Cancer 88: 579-585, 2003.
24. Rafnar T, Vermeulen SH, Sulem P, Thorleifsson G, Aben KK, Witjes JA, Grotenhuis AJ, Verhaegh GW, Hulsbergen-van de Kaa CA, Besenbacher S, et al: European genome-wide association study identifies SLC14A1 as a new urinary bladder cancer susceptibility gene. Hum Mol Genet 20: 4268-4281, 2011.

25. Henttu P and Vihko P: Prostate-specific antigen and human glandular kallikrein: two kallikreins of the human prostate. Ann Med 26: 157-164, 1994

26. Young CY, Andrews PE and Tindall DJ: Expression and androgenic regulation of human prostate-specific kallikreins. J Androl 16: 97-99, 1995. 